\title{
The effect of incident tuberculosis on
} immunological response of HIV patients on highly active anti-retroviral therapy at the \section{university of Gondar hospital, northwest Ethiopia: a retrospective follow-up study}

\author{
Abate Assefa ${ }^{1 *}$, Baye Gelaw ${ }^{1}$, Gebeyaw Getnet ${ }^{2}$ and Gashaw Yitayew ${ }^{3}$
}

\begin{abstract}
Background: Human immunodeficiency virus (HIV) infection is usually complicated by high rates of tuberculosis (TB) co-infection. Impaired immune response has been reported during HIV/TB co-infection and may have significant effect on anti-retroviral therapy (ART). TB/HIV co - infection is a major public health problem in Ethiopia. Therefore, the aim of the study was to assess the effect of TB incidence on immunological response of HIV patients during ART.

Methods: A retrospective follow-up study was conducted among adult HIV patients who started ART at the University of Gondar Hospital. Changes in CD4+ T - lymphocyte count and incident TB episodes occurring during 42 months of follow up on ART were assessed. Life table was used to estimate the cumulative immunologic failure. Kaplan-Meier curve was used to compare survival curves between the different categories. Cox-proportional hazard model was employed to examine predictors of immunological failure.

Results: Among $400 \mathrm{HIV}$ patients, 89(22.2\%) were found to have immunological failure with a rate of 8.5 per 100 person-years (PY) of follow-up. Incident TB developed in 26(6.5\%) of patients, with an incidence rate of 2.2 cases per 100 PY. The immunological failure rate was high (20.1/100PY) at the first year of treatment. At multivariate analysis, Cox regression analysis showed that baseline CD4+ T - cell count $<100 \mathrm{cell} / \mathrm{mm}^{3}$ (adjusted hazard ratio (AHR) 1.8; 95\%Cl: $1.10-2.92, p=0.023$ ) and being male sex (AHR 1.6; 95\%Cl: $1.01-2.68, p=0.046$ ) were found to be significant predictors of immunological failure. There was borderline significant association with incident TB (AHR 2.2; 95\%Cl: 0.94 - 5.09, $\mathrm{p}=0.06$ ). The risk of immunological failure was significantly higher (38.5\%) among those with incident TB compared with TB - free (21.1\%) (Log rank $\mathrm{p}=0.036)$.

Conclusions: High incidence of immunological failure occurred within the first year of initiating ART. The proportions of patients with impaired immune restoration were higher among patients with incident TB. Lower baseline CD4+ $T$ - cells count of $<100$ cells $/ \mathrm{mm}^{3}$ and being male sex were significant predictors of immunological failure. The result highlighted the beneficial effects of earlier initiation of ART on CD4+ T - cell count recovery.
\end{abstract}

Keywords: Anti-retroviral therapy, Immunological failure, Incident TB

\footnotetext{
* Correspondence: abezew@gmail.com

'Department of Medical Microbiology, College of Medicine and Health Sciences, School of Biomedical and Laboratory Sciences, University of Gondar, Gondar, Ethiopia

Full list of author information is available at the end of the article
} 


\section{Background}

Despite recent advances in anti-retroviral therapy (ART), human immunodeficiency virus (HIV) infections and the resulting acquired immunodeficiency syndrome (AIDS) remain an important cause of morbidity and mortality worldwide with 2.6 million new cases and 1.8 million deaths by the year 2009 [1]. In Ethiopia, according to the 2007 single point HIV prevalence estimate, there were 1,216,908 adult people living with HIV (PLHIV), and of these 397,818 expected to take ART treatment by the year 2010 [2]. On the other hand, tuberculosis (TB) caused by Mycobacterium tuberculosis, remains the leading causes of death from infectious diseases worldwide. In 2012, about 8.6 million incident TB and 1.3 million deaths due to TB were reported globally. The majority of TB cases occurred in Asian (58\%) and African (27\%) countries [3].

In developing countries, TB remains a major public health threat among HIV-infected individuals [3,4]. HIV is the most potent risk factor for TB and TB is the leading cause of morbidity and mortality in HIV/AIDS patients [5,6]. Tuberculosis enhances progression of HIV infection and HIV increases the risk of infection as well as reactivation of latent tuberculosis. It is estimated that $50-60 \%$ of PLHIV will develop TB disease in their lifetime in contrast with HIV negative persons, whose lifetime risk is only $10 \%[4,7]$. The proportion of TB cases co-infected with HIV is highest in African countries. In African countries, about $37 \%$ of TB cases were co-infected with HIV which accounted for $75 \%$ of TB cases among HIV positive people worldwide [3]. In 2007, based on Federal HIV/AIDS Prevention and Control Office report in Ethiopia, the TB/HIV co-infection rate was $20-50 \%$ [8]. According to WHO report, in 2012 the incidence of TB infection in Ethiopia was 247 per 100,000 people and 10.2\% of them were estimated to have co-infection with HIV [3].

With the advent of ARV drugs, HIV/AIDS has become a treatable chronic disease. Effective anti-retroviral therapy (ARV) therapy is usually convoyed by an increase in the number of $\mathrm{CD} 4+\mathrm{T}$ - cells and the functional restoration of patents' immune response and decline in HIV viral load as well. However, the requirement of regular and lifelong medication of HIV patient is challenged with emergencies of treatment failure [8-10]. Impaired immunological recovery may indicate incomplete suppression of plasma HIV RNA which results ARV drug resistance [9]. HIV treatment failure can be defined as progression of disease after ART initiation. Anti-retroviral treatment failure can be assessed clinically, immunologically and virologically. However, on the basis of clinical criteria treatment failure can't be concluded. Despite viral load testing is preferred approach for monitoring ART response, in resource limited settings, immunological failure criteria, trends in CD4+ T - cells counts over time, remains the strongest predictor of treatment failure [8].
The recovery of CD4+ T - cells count during ART in HIV/TB co-infected patients is less clear. However, studies assessing immune responses to ART have found poor CD4+ T - cells recovery to occur in patients who develop incident TB after initiating ART [11-16]. Moreover, in spite of HIV statuses sever CD4+ T -lymphocytopenia has been observed in TB patients [17]. An in vitro study indicated that TB infection impairs cellular immune responses through M. tuberculosis-induced apoptosis of $\mathrm{T}$ - cells [18]. Therefore, TB may act as a cofactor that accelerates the impairment of the immune function and shortens survival of HIV - infected individuals. Although TB/HIV coinfection is a major public health problem in Ethiopia, no studies have reported the effect of TB on immunological responses of HIV patients during ART. Hence, assessing the effect of TB on immunological responses of HIV patients will provide information for clinicians for appropriate management of TB/HIV co-infected patients. Moreover, policy makers and health professionals can use the findings to design ART related programs. Therefore, the aim of this study was to assess the effect of incident TB on immunological response of HIV/AIDS patients during ART at the University of Gondar Hospital.

\section{Methods}

\section{Study setting and population}

The study was conducted at the University of Gondar Hospital, North-west Ethiopia, in June 2013. University of Gondar Hospital is a referral hospital with more than 400 beds serving a population of about 5 million people in North-west Ethiopia. The hospital offers a wide range of services including voluntary counseling and testing, treatment, referral services, monitoring of treatment response with CD4+ T - cells counts, follow-up and supportive care of HIV-infected individuals. ART is provided free of cost to all HIV - infected individuals in need of treatment. The study populations were those patients who are 15 years old and above and ever started ART at the University of Gondar Hospital. Patients start ART based on WHO criteria for the initiation of ART in adults and adolescents; patients with CD4+ T - cell count $<200$ cell/ $\mathrm{mm}^{3}$ or WHO stage 4 irrespective of CD4+ T - cell count or WHO stage 3 with CD4+ T - cell counts $<350$ cells/ $\mathrm{mm}^{3}$. Routine monitoring of CD4+ $\mathrm{T}$ - cell counts is performed every six months, or more frequently if clinically indicated [8]. All HIV patients were screened for TB at enrolment, and during each follow-up visit through clinical evaluation and microbiological tests and chest-radiography based on WHO national guidelines. Patients diagnosed with incident TB were treated with a standard eight months regimen with two months intensive phase, combination of 4 drugs (isoniazid, rifampicin, ethambutol and pyrazinamide), and a subsequent 6 months continuation phase, 2 drugs (isoniazid, ethambutol) [4]. Routine CD4+ T - 
lymphocyte count measurements were performed by FACS count (Becton Dickinson) every 6 months or more frequently if clinically indicated after initiating ART.

\section{Study design and data collection}

A retrospective follow-up study was conducted on patients initiating ART from the 1st of September 2007 and 30th of August 2008 at the University of Gondar Hospital. This period was selected to collect patient's information from sufficient follow-up time. Adult HIV patients whose charts were available and who had at least 6 months of follow - up (having at least two CD4+ T-cell measurements) and started on first line ART during the study period were eligible for the study. HIV/AIDS patients who had active TB (prevalent TB) at the initiation of ART and missing charts or incomplete baseline and follow-up data were excluded from the study. Changes in CD4+ T - cells count and incident TB episodes occurring during the 42 months of follow-up on ART were assessed. Socio - demographic information of the patients and clinical characteristics such as time of ART start, baseline and follow-up CD4+ T - cell count, and WHO clinical stage, co-infection with $\mathrm{TB}$, time of $\mathrm{TB}$ development and functional status were extracted from the hospital's ART register. Baseline measurements of $\mathrm{CD} 4+\mathrm{T}$ - cell count was included if performed within six months prior to ART initiation and once on treatment follow-up measurements was included if performed within \pm 2 months of the 6 month time points. Data extraction format was prepared and pretested on 20 charts. The data were extracted from patients' charts by three nurses who had ART training and experience in HIV care.

\section{Definitions}

Prevalent TB was defined as patients taking anti-TB treatment at the time of starting ART. Incident TB was defined as a new active TB developed after initiation of ART. Immunological failure was defined based on WHO criteria: decrease in CD4+ T - cell count to pre -ART level or below, decrease in CD4+ T - cell count from on-treatment peak value by more than $50 \%$ or persistent CD4+ T - cell count $<100$ cells $/ \mathrm{mm}^{3}$ after six months of therapy [8]. Patients, who were died, transfer out or, lost to - follow-up or didn't show the event until the last visit was considered as censored.

\section{Statistical methods}

Immunologic failure rates were calculated per 100 person years at risk. Data were entered and cleaned by using Epi-Info version.3.5.3 then exported to Statistical Package for the Social Sciences (SPSS) version 20. Descriptive analyses were used to determine baseline sociodemographic and clinical characteristics of the patients.
Life table was used to estimate the cumulative probabilities of immunologic failure. Kaplan-Meier survival curve was used to estimate the median survival time from initiation of ART to immunologic failure. Bivariate and multivariate Cox-proportional hazard model was employed to identify predictors of immunological failure. Hazard Ratio (HR) with 95\% confidence intervals were computed and p-value $<0.05$ was considered statistically significant for all cases.

\section{Ethical approval}

The study was reviewed and approved by the Institutional Review Board (IRB) of the University of Gondar. Official permission was obtained from University of Gondar Hospital management. The patient records were anonymized and de-identified prior to analysis. Individual records were coded and accessed only by research staff.

\section{Results}

Baseline socio-demographic characteristics of patients A total of 606 adult HIV/AIDS patients were newly enrolled to HIV care clinic from the 1st of September 2007 and 30th of August 2008 but 122 patients were excluded due to missing charts or incomplete baseline and followup data. Among 484 HIV patients who had at least 6 months of follow-up, 84(17.4\%) had active TB at the initiation of ART and the analysis was restricted to those who did not have active TB at ART start. Therefore, a total of 400 adult HIV/AIDS patients record were analyzed. Of the 400 adult HIV/AIDS patients who met the inclusion criteria for the study, 315 (78.8\%) remained within the programme at study censorship, 4 (1\%) died, $67(16.8 \%)$ transferred out and 14(3.5\%) were lost to follow - up from the programme. Of 400 adult HIV/AIDS patients, the majority (64.5\%) were females. The median age of patients at ART start was 33 years (Inter Quartile Range (IQR) $=27-40$ years) and almost half of the patients were married (50.5\%). One hundred seventeen (29.3\%) of the study participants had no formal education and only $62(15 \%)$ patients were employed (Table 1$)$.

\section{Baseline clinical characteristics of patients}

During ART enrolment more than half (52\%) of patients were at WHO clinical stage III. At the time of ART initiation, patients had advanced immunodeficiency with the median baseline CD4+ T - cell counts of 152 cells $/ \mathrm{mm}^{3}$ $\left(\mathrm{IQR}=82-203\right.$ cells $\left./ \mathrm{mm}^{3}\right)$. One hundred and twenty seven $(31.8 \%)$ of patients had baseline CD4+ T - cell counts $<100$ cells $/ \mathrm{mm}^{3}$. Majority of the patients started treatment with zidovudine (AZT)/lamivudine (3TC)/nevirapine (NVP) or efavirenz (EFV) (47.3\%) followed by tenofobir (TDF)/3TC/NVP or EFV (40.5\%) and stavudine (D4T)/3TC/NVP or EFV (12.3\%) based combination first 
Table 1 Baseline socio-demographic characteristics of HIV/AIDS patients who started ART from September 2007 to August 2008 at the University of Gondar Hospital

\begin{tabular}{|c|c|c|}
\hline Variable & $\mathrm{n}$ & $\%$ \\
\hline \multicolumn{3}{|l|}{ Gender } \\
\hline Male & 142 & 35.5 \\
\hline Female & 258 & 64.5 \\
\hline \multicolumn{3}{|l|}{ Age } \\
\hline $16-30$ & 165 & 41.3 \\
\hline $31-50$ & 211 & 52.8 \\
\hline$>50$ & 24 & 6.0 \\
\hline \multicolumn{3}{|l|}{ Religion } \\
\hline Orthodox & 364 & 91.0 \\
\hline Muslim & 33 & 8.3 \\
\hline Others & 3 & 0.8 \\
\hline \multicolumn{3}{|l|}{ Residence } \\
\hline Urban & 318 & 79.5 \\
\hline Rural & 82 & 20.5 \\
\hline \multicolumn{3}{|l|}{ Marital status } \\
\hline Single & 63 & 15.8 \\
\hline Married & 202 & 50.5 \\
\hline Divorced & 87 & 21.8 \\
\hline Widowed & 48 & 12.0 \\
\hline \multicolumn{3}{|l|}{ Educational status } \\
\hline Illiterate & 117 & 29.3 \\
\hline Primary & 111 & 27.8 \\
\hline Secondary & 129 & 32.3 \\
\hline Tertiary & 43 & 10.8 \\
\hline \multicolumn{3}{|c|}{ Occupational status } \\
\hline Employed & 62 & 15.5 \\
\hline Unemployed & 193 & 48.3 \\
\hline Housewife & 80 & 20.0 \\
\hline Merchant & 48 & 12.0 \\
\hline Farmer & 17 & 4.3 \\
\hline
\end{tabular}

line ARV drug regimens. Three hundred and forty $(85 \%)$ patients were working by their functional status (Table 2).

\section{Immunological failure after initiation of ART}

Study participants were followed for a minimum of 6 and a maximum of 42 months with total person-time followup of 1042.7 person-years (PY). The median number of $\mathrm{CD} 4+\mathrm{T}$ - cell counts performed per patient during the follow -up period was 7 (IQR $=6-8$ ). Of the $400 \mathrm{HIV} /$ AIDS patients who had at least 6 months of follow -up, 85 (21.3\%) patients were lost to follow - up before the study censorship. Eighty nine (22.2\%) of the patients were found to have immunological failure. Based on WHO criteria, 49 (55\%) immunological failure were defined by decrease in
CD4+ T - cell count to pre -ART level or below, 12 (13.5\%) decrease in CD4+ T - cell count from on-treatment peak value by more than $50 \%$ and 28 (31.5\%) persistent $\mathrm{CD} 4+\mathrm{T}$ - cell count below 100 cells $/ \mathrm{mm}^{3}$. The median time for occurrence of immunological failure was 6 months (IQR = 6 - 12 months). The median time for immunological failure was 6 months for both TB and TBfree cohorts. Among all 89 immunological failures, 60 $(67.4 \%)$ patients were failed at 6 month of follow-up on ART. The overall immunological failure rate of our cohort was 30 per 100PY at the end of 6 months, 20.1 per $100 \mathrm{PY}$ at the end of one year, 16.2 per $100 \mathrm{PY}$ at the end of 18 months, 13.0 per $100 \mathrm{PY}$ at the end of two years, 11.1 per $100 \mathrm{PY}$ at the end of 30 months, 10.8 per $100 \mathrm{PY}$ at the end of three years and 8.5 per $100 \mathrm{PY}$ at the end of 42 months of follow-up. The cumulative probability of survival of patients from immunological failure at the end of 6 months was $85 \%$ while at the end of one year was $79 \%$, at the end of three years $78 \%$ and at the end of 42 months $75 \%$ (Figure 1).

Active TB developed in 26(6.5\%) patients within 42 months on ART, with an incidence rate of 2.2 cases per 100 PY of follow-up. The median time for development of incident TB during the follow-up was 9.5 months (IQR, 5.5 - 16.5 months). Among those who developed TB during the follow-up time, 17(57.7\%) of the incident TB occurred within the first year of initiating ART. After 42 months on ART, the risk of immunologic failure was $38.5 \%$ versus $21.1 \%$ among patients with and without incident TB respectively $(\log$ rank $\mathrm{p}=0.036)$ (Figure 2$)$.

Kaplan Meier survival analysis showed that the probability of survival of patients from immunological failure was significantly lower among patients with baseline CD4+ T - cell count $<100$ cells $/ \mathrm{mm}^{3}$ when compared to those CD4+ T - cell count of 100 cells $/ \mathrm{mm}^{3}$ and above ( $\log$ rank test, $\mathrm{p}=0.007$ ) (Figure 3 ). In addition, male patients showed lower immunological failure survival than females $(\log$ rank $\mathrm{p}=0.031)$ (Figure 4).

In multivariate Cox regression analysis baseline CD4+ T - cell counts level $<100$ cells $/ \mathrm{mm}^{3}$ (adjusted hazard ratio (AHR) 1.7, 95\% CI: $1.11-2.64, \mathrm{p}=0.015$ ) and being male sex (AHR 1.6, 95\% CI: $1.01-2.37, \mathrm{p}=0.043$ ) were found to be significant predictors of immunological failure. Even though the survival from immunological failure was significantly lower among patients with incident $\mathrm{TB}(\mathrm{p}=$ 0.036), Cox regression analysis showed borderline significant association between incident TB and immunological failure (HR 1.9, 95\% CI: 0.97 - 3.7, p = 0.06) (Table 3).

\section{Discussion}

The baseline socio-demographic and immunological characteristics of this cohort were similar to other ART cohorts in sub-Saharan Africa, in which the majority of patients started ART at an advanced stage of the diseases and majority of the patients were females $[6,10,12,19]$. In 
Table 2 Baseline clinical characteristics and TB incidence of HIV/AIDS patients who started ART from September 2007 to August 2008 at the University of Gondar Hospital

\begin{tabular}{|c|c|c|c|}
\hline Variable & Total & Incident TB+ & Incident TB- \\
\hline Female sex (n[\%]) & $258(64.5)$ & $18(69.2)$ & $240(64.2)$ \\
\hline Age (years, mean [SD]) & $34.37 \pm 9.29$ & $35.4 \pm 8.8$ & $34.3 \pm 9.3$ \\
\hline \multicolumn{4}{|l|}{ WHO HIV clinical stage (n[\%]) } \\
\hline I & $57(14.3)$ & $2(3.5)$ & $55(96.5)$ \\
\hline$\|$ & $86(21.5)$ & $6(7.0)$ & 80(93.0) \\
\hline III & 208(52.0) & $13(6.2)$ & 195(93.8) \\
\hline IV & $49(12.3)$ & $5(10.2)$ & $44(89.8)$ \\
\hline CD4 count (cells $/ \mathrm{mm}^{3}$, median [IQR]) & $152(82,203)$ & $98(58,201.75)$ & $153(86,203)$ \\
\hline \multicolumn{4}{|l|}{ CD4 count (cell/mm $\left.{ }^{3}, \mathrm{n}[\%]\right)$} \\
\hline $0-99$ & 127(31.8) & 13(10.4) & 112(89.6) \\
\hline$\geq 100$ & $170(42.5)$ & $13(4.7)$ & 262(95.3) \\
\hline \multicolumn{4}{|l|}{ Initial ART Regimen (n[\%]) } \\
\hline $\mathrm{d} 4 \mathrm{~T} / 3 \mathrm{TC} / \mathrm{NVP}$ or EFV & $49(12.3)$ & $4(8.2)$ & 45(91.8) \\
\hline $\mathrm{AZT} / 3 \mathrm{TC} / \mathrm{NVP}$ or EFV & 189(47.3) & $15(7.9)$ & 174(92.1) \\
\hline TDF/3TC/NVP or EFV & $162(40.5)$ & $7(4.3)$ & 155(95.7) \\
\hline \multicolumn{4}{|l|}{ Functional status ( $\mathrm{n}[\%]$ ) } \\
\hline Working & $340(85.0)$ & 20(5.9) & $320(94.1)$ \\
\hline Ambulatory & 49(12.3) & $4(8.2)$ & 45(91.8) \\
\hline Bed ridden & $11(2.8)$ & $2(18.2)$ & $9(81.8)$ \\
\hline
\end{tabular}

d4T: stavudine; 3TC: lamivudine; NVP: nevirapine; AZT: zidovudine; EFV: efavirenz; TDF: tenofobir; TB: tuberculosis; HIV: human immunodeficiency virus; ART: antiretroviral therapy; IQR: interquartile range; SD: standard deviation; WHO: world health organization.

resource-limited settings evaluation of treatment outcomes mainly relies on immunological findings. Effective ARV therapy is usually convoyed by quantitative and functional restoration of patents' immune response. Immunological failure may indicate incomplete suppression of plasma viral load [9]. In our study, 89 (22.2\%) patients were experienced immunological failure within 42 months of follow-up. Of patients who have had immunological

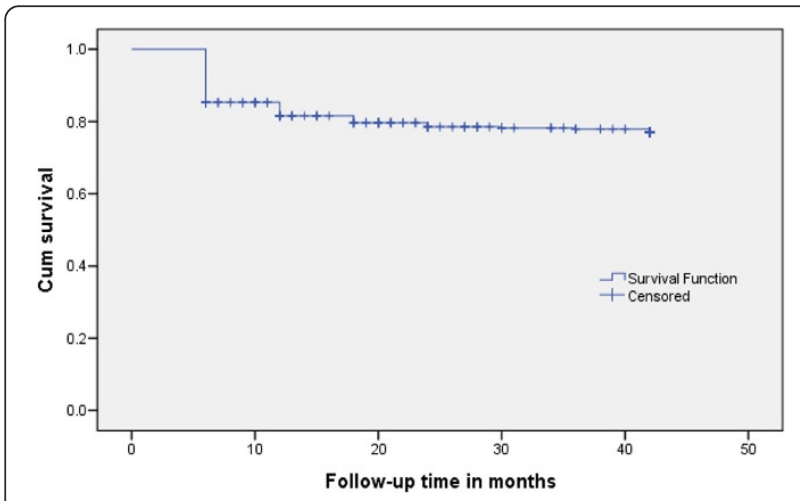

Figure 1 Kaplan-Meier curve for immunological failure of HIV/ AIDS patients taking ART. The Kaplan-Meier curve indicated the trends of cumulative survival of patients from immunological failure within 42 months of follow up on ART. failure, 60(67.4\%) patients were failed at 6 month of follow up. The immunological failure rate of our cohort was 8.5 per 100 patient-years. This finding is almost in line with the report from Debremarkos, Ethiopia, in which the immunological failure rate was 8 per 100 PY [19]. However, lower findings were reported from Latin America and Asia with failure rate of 2.57 per $100 \mathrm{PY}$ and 1.1per $100 \mathrm{PY}$ of follow - up respectively [20].

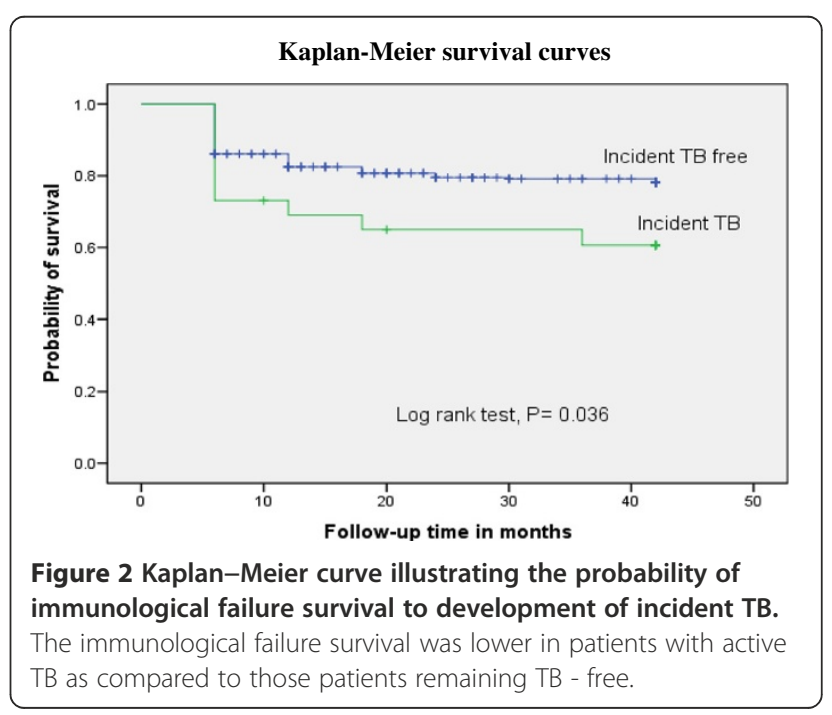




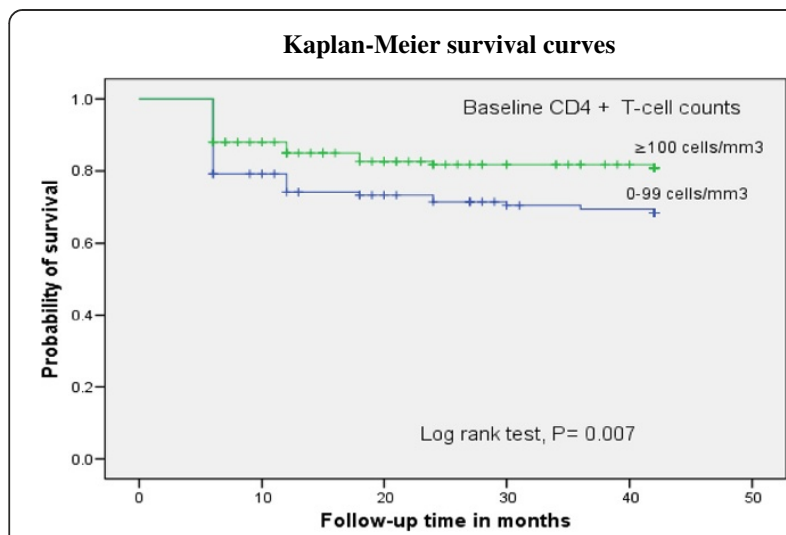

Figure 3 Kaplan-Meier curve illustrating the probability of survival from immunological failure based on baseline CD4+ T-cell count. The survival from immunological failure was lower in patients with baseline CD4+ T - cell count of 0-99 cells $/ \mathrm{mm}^{3}$ as compared to those with CD4+ T - cell count of 100 cells $/ \mathrm{mm}^{3}$ and above,

In our cohort, the immunological failure rate showed time-related downward trend with lowest failure rate occurred at the end of the follow-up. The majority of immunological failure in our cohort was occurred at 6 months of ART enrolment (30 per $100 \mathrm{PY}$ ) which is concordant with findings reported in other African countries [6,19]. This might be due to the initiation of ART at an advanced stage of HIV/AIDS diseases. Baseline lower CD4+ $\mathrm{T}$ - cell counts associated with poor $\mathrm{CD} 4+\mathrm{T}$ - cell count restoration and maintain long term lower immune response [10,19,21-23].

In this study, the log rank test showed that the immunological failure free survival proportion was significantly lower among patients with incident $\mathrm{TB}$ when compared to those patients remaining TB-free for the same follow-up time on ART. However, in the multivariate Cox regression

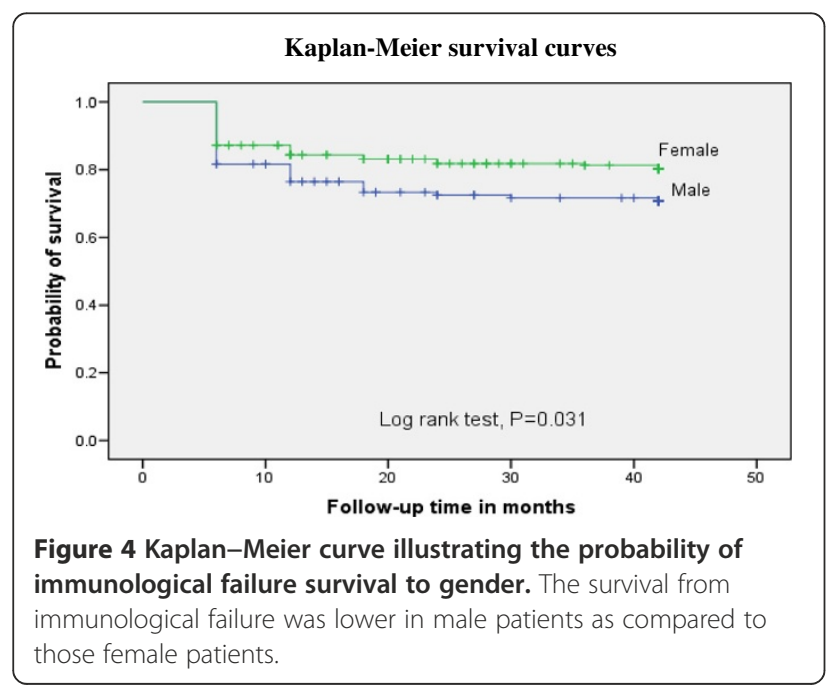

analysis we observed borderline significant association between incident TB and immunological failure. This may be due to relatively small number of cases with incident TB. Different studies reported that despite TB treatment patients who developed TB after ART initiation were more likely to have lower immune recovery. Studies on South African [11] and Ugandan [12] cohorts of HIV patients initiated on ART, incident TB was associated with suboptimal CD4+ $\mathrm{T}$ - cell responses. Furthermore, a study from Senegal indicated that independent of HIV status development of incident TB causes severe CD4+ T-lymphocytopenia [17]. These findings may suggest that incident $\mathrm{TB}$ during ART is associated with long lasting immune suppression. Low baseline CD4+ T - cell counts at enrolment to an ART programme is associated with increased risks of TB and of mortality during the first year of ART [6,7]. In this study the lower baseline CD4+ T cell counts may expose patients to an increased risk of developing incident $\mathrm{TB}$ which can in turn contribute to immunological failure. Another explanation for the lower CD4+ T - cell recovery in patients with incident TB during ART may be due to decreased adherence to ART during TB treatment because of high pill burden and side-effects [24].

The most important finding of our study was that in multivariate Cox regression analysis lower baseline CD4+ $\mathrm{T}$ - cell counts were independently associated with immunological failure. This is supported by other studies conducted in Debremarkos, Ethiopia [19] and Thailand $[21,22]$ in which immunological failures were significantly associated with lower baseline CD4+ $\mathrm{T}$ - cell counts. Moreover, this finding is concordant with other reports where immune restoration is largely dependent on baseline CD4+ T - cell count and thus the timing of ART initiation is important in order to optimize the CD4+ T - cell response to therapy [23]. These reports may highlight that patients with low CD4+ T - cells count at baseline have poor long term CD4+ T - cells responses. Therefore, our finding supports the new WHO 2013 recommendations of expanding eligibility for ART initiation to CD4+ T - cell counts $\leq 500$ cells/ $\mathrm{mm}^{3}$ for all adults and children above 5 years [25].

Although the causal relationship is not known, keeping the report from Uganda [12] immunological failure was also associated with male sex. Advanced baseline WHO clinical stages and old age groups were significant predictors of poor immunological responses during ART [19]. However, in our study none of these factors were found to be associated with non-immunological responses of patients on ART. Unidentified factors such as opportunistic diseases and/or malnutrition might be the prime determinants of the immune recovery in the current study subjects. 
Table 3 Cox-proportional hazard analysis of factors associated with immunological failure among HIV/AIDS patients who started ART from September 2007 to August 2008 at the University of Gondar Hospital

\begin{tabular}{|c|c|c|c|c|c|c|}
\hline \multirow[t]{3}{*}{ Variables } & \multicolumn{2}{|c|}{ Immunological failure } & \multirow[t]{3}{*}{ Crude HR $(95 \% \mathrm{Cl})$} & \multirow[t]{3}{*}{$P$} & \multirow[t]{3}{*}{ Adjusted HR $(95 \% \mathrm{Cl})$} & \multirow[t]{3}{*}{$P$} \\
\hline & No & Yes & & & & \\
\hline & no (\%) & no (\%) & & & & \\
\hline \multicolumn{7}{|l|}{ Gender } \\
\hline Female & 102(71.8) & $40(28.2)$ & 1 & & 1 & \\
\hline Male & $209(81)$ & 49(19) & $1.54(1.02-2.34)$ & 0.042 & 1.6(1.01-2.68) & 0.046 \\
\hline \multicolumn{7}{|l|}{ Age (in year) } \\
\hline $16-30$ & 130(78.8) & $35(21.2)$ & 1 & & & \\
\hline $31-50$ & 164(77.7) & $47(22.3)$ & $1.06(.68-1.63)$ & 0.812 & & \\
\hline$>50$ & 17(70.8) & $7(29.2)$ & $1.37(.61-3.09)$ & 0.443 & & \\
\hline \multicolumn{7}{|l|}{ Education } \\
\hline Primary and below & 175(76.8) & $53(23.2)$ & $1.12(.75-1.74)$ & 0.546 & & \\
\hline Secondary and above & 136(79.1) & $36(20.9)$ & 1 & & & \\
\hline \multicolumn{7}{|l|}{ WHO HIV clinical stage } \\
\hline । & $47(82.5)$ & $10(17.5)$ & 1 & & & \\
\hline$\|$ & $65(75.6)$ & $21(24.4)$ & $1.44(.69-3.06)$ & 0.344 & & \\
\hline III & $161(77.4)$ & $47(22.6)$ & $1.31(.66-2.59)$ & 0.438 & & \\
\hline IV & 38(77.6) & $11(22.4)$ & $1.32(.56-3.12)$ & 0.525 & & \\
\hline \multicolumn{7}{|c|}{ Baseline CD4+ count (cells $/ \mathrm{mm}^{3}$ ) } \\
\hline $0-99$ & $87(69.6)$ & $38(30.4)$ & $1.72(1.13-2.62)$ & 0.012 & 1.8(1.10-2.92) & 0.023 \\
\hline$\geq 100$ & $224(81.5)$ & $51(18.5)$ & 1 & & 1 & \\
\hline \multicolumn{7}{|l|}{ Initial ART regimen } \\
\hline D4T/3TC/NVP or EFV & 40(81.6) & $9(18.4)$ & 1 & & & \\
\hline AZT/3TC/NVP or EFV & $141(74.6)$ & $48(25.4)$ & $0.90(.43-1.89)$ & 0.785 & & \\
\hline TDF/3TC/NVP or EFV & 130(80.2) & $32(19.8)$ & $1.29(.83-2.02)$ & 0.262 & & \\
\hline \multicolumn{7}{|l|}{ Functional status } \\
\hline Working & $262(77.1)$ & $78(22.9)$ & 1 & & & \\
\hline Ambulatory & 39(79.6) & $10(20.4)$ & 1.44(.72-2.92) & 0.301 & & \\
\hline Bed ridden & 10(90.9) & $1(9.1)$ & $1.26(.58-2.75)$ & 0.555 & & \\
\hline \multicolumn{7}{|l|}{ Incident TB } \\
\hline Yes & $16(61.5)$ & 10(38.5) & 1.92(.99-3.72) & 0.050 & $2.2(0.94-5.09)$ & 0.063 \\
\hline No & 295(78.9) & $79(21.1)$ & 1 & & 1 & \\
\hline
\end{tabular}

d4T: stavudine; 3TC: lamivudine; NVP: nevirapine; AZT: zidovudine; EFV: efavirenz; TDF: tenofobir; TB: tuberculosis; HIV: human immunodeficiency virus; ART: antiretroviral therapy; IQR: inter-quartile range; SD: standard deviation; WHO: world health organization; HR: hazard ratio, P: p-value.

\section{Study limitations}

As a retrospective design our study had limitations. We excluded a large number of patient charts that could not be verified by chart review due to unavailability of full information which may have introduced bias. Moreover, because of the nature of the study design, it was difficult to control all possible confounders like body mass index and opportunistic infections other than TB. The sample size was also too small to include representative incident TB cases and with large sample size the effect of TB on immunological failure could be more elaborated. Given that virologic response is the preferred standard for monitoring ART, this study only assessed immunological responses of the patients and as a result that immunological failure could be related to viral resistance or non adherence. Therefore, for better understanding of the association between incident TB and CD4+ T - cell count recovery of HIV patients during ART prospective cohort study should be considered.

\section{Conclusion}

High immunological failure rate in our cohort was occurred at six months of ART enrolment. The proportions of patients with impaired immune restoration were 
significantly higher among patients who developed incident TB during ART. Lower baseline CD4+ T - cell count of $<100$ cells $/ \mathrm{mm}^{3}$ and being male sex were found to be significant predictors of immunological failure. The timing of initiation of ART was major determinants of the change in CD4+ T - cells count recovery. The result highlighted the beneficial effects of earlier initiation of ART on CD4+ T - cells recovery and strengthening early detection of TB through active screening and appropriate management of TB patients.

\section{Competing interests}

The authors declare that they have no competing interests.

\section{Authors' contributions}

AA proposed the initial idea for the study. AA, BG contributed to the study design. All authors collected all the data. All authors analyzed and interpreted the data. AA prepared the manuscript for publication. All authors read and approved the final manuscript.

\section{Acknowledgements}

The authors are grateful to staff of antiretroviral clinic database center at University of Gondar Hospital for their unreserved help and facilitation of this study.

\section{Author details}

${ }^{1}$ Department of Medical Microbiology, College of Medicine and Health Sciences, School of Biomedical and Laboratory Sciences, University of Gondar, Gondar, Ethiopia. ${ }^{2}$ Department of Medical Parasitology, College of Medicine and Health Sciences, School of Biomedical and Laboratory Sciences, University of Gondar, Gondar, Ethiopia. ${ }^{3}$ Bahir Dar Regional Laboratory institute, Bahir Dar, Ethiopia.

Received: 26 February 2014 Accepted: 18 August 2014 Published: 27 August 2014

\section{References}

1. UNAIDS: Report on the Global AIDS Epidemic. Geneva, Switzerland: UNAIDS; 2010.

2. The Federal HIV/AIDS Prevention and Control Office: Single Point HIV Prevalence Estimate. Ethiopia, Addis Ababa: Ministry of Health; 2007.

3. World Health Organization: Global Tuberculosis Report 2013. Geneva, Switzerland: World Health Organization; 2013.

4. Federal ministry of health: Tuberculosis, Leprosy and TB/HIV Prevention and Control Program Manual. Ethiopia, Addis Ababa: Ministry of Health; 2008.

5. Casseb J, Fonseca LA, Medeiros LA, Gonsalez CR, Lagonegro ER, Veiga AP, da Silva DC, Mendonça M, Duarte AJ: Tuberculosis among HIV-1-infected subjects in a tertiary out-patient service in São Paulo City, Brazil. Rev Inst Med Trop Sao Paulo 2012, 54(5):257-259.

6. Gupta A, Wood R, Kaplan R, Bekker LG, Lawn SD: Prevalent and incident tuberculosis are independent risk factors for mortality among patients accessing antiretroviral therapy in South Africa. PLoS One 2013, 8(2):e55824

7. Federal ministry of health: Implementation Guideline for TB/HIV Collaborative Activities in Ethiopia. Ethiopia, Addis Ababa: Ministry of Health; 2007.

8. Federal HIV/AIDS Prevention and Control Office: Guidelines for Management of Opportunistic Infections and Anti Retroviral Treatment in Adolescents and Adults in Ethiopia. Ethiopia, Addis Ababa: Ministry of Health; 2007.

9. Battegay M, Nüesch R, Hirschel B, Kaufmann GR: Immunological recovery and antiretroviral therapy in HIV-1 infection. Lancet Infect Dis 2006, 6:280-287.

10. El-Khatib Z, Katzenstein D, Marrone G, Laher F, Mohapi L, Petzold M, Morris $L$, Ekström AM: Adherence to drug-refill is a useful early warning indicator of virologic and immunologic failure among HIV patients on first-line ART in South Africa. PLoS One 2011, 6:e17518.

11. Eshun-Wilson I, Taljaard JJ, Nachega JB: Sub-optimal CD4 T-lymphocyte responses among HIV infected patients who develop TB during the first year of ART. AIDS Clin Res 2012, 3(135):1000135.

12. Hermans SM, Kiragga AN, Schaefer P, Kambugu A, Hoepelman Al, Manabe YC: Incident tuberculosis during antiretroviral therapy contributes to suboptimal immune reconstitution in a large urban HIV clinic in sub-Saharan Africa. PLoS One 2010, 5:e10527.

13. Lawn SD, Myer L, Bekker LG, Wood R: Burden of tuberculosis in an antiretroviral treatment programme in sub-Saharan Africa: impact on treatment outcomes and implications for tuberculosis control. AIDS 2006, 20:1605-1612.

14. Andersen AB, Range NS, Changalucha J, God GP, Kidola J, Faurholt-Jepsen D, Krarup H, Grewal HMS, Friis H: CD4 lymphocyte dynamics in Tanzanian pulmonary tuberculosis patients with and without HIV co-infection. BMC Infect Dis 2012, 12:66.

15. Morris L, Martin DJ, Bredell H, Nyoka SN, Sacks L, Pendle S, Page-Shipp L, Karp CL, Sterling TR, Quinn TC, Chaisson RE: Human immunodeficiency virus-1 RNA levels and CD4 lymphocyte counts, during treatment for active tuberculosis, in South African patients. J Infect Dis 2003, 187(12):1967-1971.

16. Brouwer M, Gudo PS, Simbe CM, Perdigão P: The effect of tuberculosis and antiretroviral treatment on CD4+ cell count response in HIV-positive tuberculosis patients in Mozambique. BMC Public Health 2012, 12:670.

17. Kony SJ, Hane AA, Larouzé B, Samb A, Cissoko S, Sow PS, Sané M, Maynart M, Diouf G, Murray JF: Tuberculosis-associated severe CD4-Tlymphocytopenia in HIV-seronegative patients from Dakar. J Infect 2000 41:167-171.

18. Zhang Q, Sugawara I: Immunology of tuberculosis. World J Exp Med 2012 2(4):70-74

19. Melsew YA, Terefe MW, Tessema GA, Ayele TA: Rate of immunological failure and its predictors among patients on highly active antiretroviral therapy at debremarkos hospital, northwest Ethiopia: a retrospective follow up study. J AIDS Clin Res 2013, 4:211.

20. Renaud-Théry F, Duncombe C, Kerr S, Thierry S, Perriëns J: Adult Antiretroviral Therapy in Resource Limited Settings: A Systematic Review of First-Line Failure and Attrition Rates. Geneva: World Health Organization; 2008.

21. Khienprasit N, Chaiwarith R, Sirisanthana T, Supparatpinyo K: Incidence and risk factors of antiretroviral treatment failure in treatment-naïve HIV-infected patients at Chiang Mai University Hospital. Thailand AIDS Res Ther 2011, 8:42.

22. Srasuebkul P, Ungsedhapand C, Ruxrungtham K, Boyd MA, Phanuphak P, Cooper DA, Law MG: Predictive factors for immunological and virological endpoints in Thai patients receiving combination antiretroviral treatment. HIV Med 2007, 8(1):46-54.

23. Kigozi BK, Sumba S, Mudyope P, Namuddu B, Kalyango J, Karamagi C, Odere M, Katabira E, Mugyenyi P, Ssali F: The effect of AIDS defining conditions on immunological recovery among patients initiating antiretroviral therapy at joint clinical research centre, Uganda. AIDS Res Ther 2009, 6:17.

24. Lawn SD, Myer L, Bekker LG, Wood R: CD4 cell count recovery among HIV-infected patients with very advanced immunodeficiency commencing antiretroviral treatment in sub-Saharan Africa. BMC Infect Dis 2006, 6:59.

25. Hirnschall G, Harries AD, Easterbrook PJ, Doherty MC, Ball A: The next generation of the World Health Organization's global antiretroviral guidance. SJIAS 2013, 16:18757.

\section{doi:10.1186/1471-2334-14-468}

Cite this article as: Assefa et al: The effect of incident tuberculosis on immunological response of HIV patients on highly active anti-retroviral therapy at the university of Gondar hospital, northwest Ethiopia: a retrospective follow-up study. BMC Infectious Diseases 2014 14:468.

\section{Submit your next manuscript to BioMed Central and take full advantage of:}

- Convenient online submission

- Thorough peer review

- No space constraints or color figure charges

- Immediate publication on acceptance

- Inclusion in PubMed, CAS, Scopus and Google Scholar

- Research which is freely available for redistribution 